Original Article

\title{
SIMVASTATIN ATTENUATES RENAL FAILURE IN MICE WITH A 5/6 SUBTOTAL NEPHRECTOMY
}

\author{
PUTU NITA CAHYAWATI ${ }^{1,3}$, NGATIDJAN ${ }^{1}$, DWI CAHYANI RATNA SARI², MUHAMMAD MANSYUR ROMI², \\ NUR ARFIAN ${ }^{2}$
}

1Department of Pharmacology and Therapy, Faculty of Medicine, Universitas Gadjah Mada, Yogyakarta, Indonesia, ${ }^{2}$ Department of Anatomy, Faculty of Medicine, Universitas Gadjah Mada, Yogyakarta, Indonesia, ${ }^{3}$ Department of Pharmacology and Pharmacy, Faculty of Medicine, Warmadewa University, Bali, Indonesia

Email: nur_arfian@ugm.ac.id

Received: 18 Apr 2016 Revised and Accepted: 09 Mar 2017

\begin{abstract}
Objective: The objective of this study to investigate the effect of simvastatin on kidney fibrosis in mice with a 5/6 subtotal nephrectomy.

Methods: Thirty adults ( 3 mo old) male Swiss mice were submitted to a 5/6 subtotal nephrectomy and studied after 14 d. Animals were divided into five groups: $5 / 6$ subtotal nephrectomy ( $\mathrm{SN}, \mathrm{n}=6$ ), sham operation ( $\mathrm{SH}, \mathrm{n}=6$ ), simvastatin $5.2 \mathrm{mg} / \mathrm{kg}$ body weight (SIM- $1, \mathrm{n}=6$ ), simvastatin $10.4 \mathrm{mg} / \mathrm{kg}$ body weight (SIM-2, n=6), and simvastatin $20.8 \mathrm{mg} / \mathrm{kg}$ body weight (SIM-3, n=6) groups. At sacrifice, kidneys were harvested for morphology (glomerulosclerosis (GS), tubular injury and interstitial fibrosis), immunostaining ( $\alpha$-smooth muscle actin ( $\alpha$-SMA)) and platelet-derived growth factor receptor beta (PDGF-R $\beta$ ) and reverse transcriptase-polymerase chain reaction (RT-PCR) (MCP-1, ICAM-1, nephrin, and podocin) analysis.
\end{abstract}

Results: Glomerulosclerosis, tubular injury and interstitial fibrosis in the simvastatin group was significantly lower than $\mathrm{SN}$ group ( $<<0.05$ ). Simvastatin significantly reduced $\alpha$-SMA expression $(3.61 \pm 1.06$ vs $7.91 \pm 1.26, p<0.05$, SIM- 1 vs SN; $2.86 \pm 0.61$ vs $7.91 \pm 1.26$, $p<0.05$, SIM-2 vs $S N$; $1.71 \pm 0.50$ vs $7.91 \pm 1.26$, p $<0.05$, SIM-3 vs SN), MCP- 1 was markedly expressed in the $5 / 6$ subtotal nephrectomy kidneys and was reduced with simvastatin ( $1.4 \pm 0.64$ vs $0.57 \pm 0.23$, $\mathrm{p}<0.05$, SN vs SIM- $1 ; 1.4 \pm 0.64$ vs $0.6 \pm 0.26, \mathrm{p}<0.05$, SN vs SIM- $2 ; 1.4 \pm 0.64$ vs $0.52 \pm 0.21$, $S N$ vs $S I M-3$, $\mathrm{p}<0.05$ ). Simvastatin did not increase nephrin expression, but it increased podocin expression significantly in the SIM-3 group.

Conclusion: Simvastatin significantly attenuated GS, tubular injury and interstitial fibrosis through the downregulation of myofibroblast expansion and inflammatory mediators in mice with a 5/6 subtotal nephrectomy.

Keywords: Simvastatin, Kidney fibrosis, Inflammatory mediator, Myofibroblast, Subtotal nephrectomy

(C) 2017 The Authors. Published by Innovare Academic Sciences Pvt Ltd. This is an open access article under the CC BY license (http://creativecommons.org/licenses/by/4.0/) DOI: http://dx.doi.org/10.22159/ijpps.2017v9i5.12261

\section{INTRODUCTION}

Chronic kidney disease (CKD) is a global health problem. The global increase in incidence and prevalence of CKD is associated with increased morbidity and mortality risks as well as a direct increase in the financial burden [1]. There are various factors which may lead to CKD such as diabetes mellitus, hypertension, infection (glomerulonephritis, chronic pyelonephritis), and urinary tract obstruction [2,3]. These diseases have the ability to cause an increase in intraglomerular pressure, barrier filtration permeability, endothelial cell dysfunction, mesangial, podocyte, and tubular cell activation, extracellular matrix synthesis, proteinuria/albuminuria and decrease glomerular filtration rate (GFR)[2].

Pharmacological therapy for CKD is primarily aims to address the underlying causes and prevent the progression of the disease. Renin angiotensin aldosteron system inhibitor (RAASI) has proven to be the most effective therapy in reducing proteinuria and slowing the progression of CKD [2]. Meanwhile, statins are the pharmacologic intervention of choice for dyslipidemia, which is the greatest risk factor for cardiovascular (CV) events and the progression of kidney disease [4].

Preclinical research in the last few decades has reported that statins have pleotropic effects, giving it the ability to inhibit the mevalonate pathway, especially the inhibition of isoprenoid metabolism $[5,6]$. One of which are for the prevention of renal fibrosis [1]. Fibrosis may be inhibited through different mechanisms, including: inhibition of Rho family proteins (RhoA and Rac-1) and reversal of podocyte damage [3, 7], inhibition of the HOXA13-USAG-1 pathway [1], inhibition of the angiotensin II/Smad pathway [8], inhibition of ACE expression and aldosterone production [9], inhibition of NF- $\mathrm{KB}$ activation, IL-1 $\beta$, TGF- $\beta 1$ and oxidative stress expression $[10,11]$, as well as inhibition of the MAPK signaling pathway [6].
However, the effect of statins in preventing CKD progression is still unclear and controversial. Statins have shown to have preventive effects on cardiovascular disorders, but no effect on the kidneys [12]. The advantages of statin use in clinical practice is also unclear, although it is likely to have an effect in preventing proteinuria depending on the dose and duration of use $[13,14]$. Therefore, we investigated the effect of simvastatin on kidney fibrosis model in mice with a $5 / 6$ subtotal nephrectomy.

\section{MATERIALS AND METHODS}

Thirty adult (3 mo old) male Swiss mice, weighing 30-40 g, obtained from Animal Care Unit, Universitas Gadjah Mada (Yogyakarta, Indonesia), were used in this study. The animals were randomized and maintained under standard laboratory conditions (at $22+2{ }^{\circ} \mathrm{C}$; $50 \pm 5 \%$ humidity; $12 / 12 \mathrm{~h}$ light/dark cycle) with accessed libitum to an animal diet and tap water [15]. All experimental procedures were conducted according to the Medical and Health Research Ethics committee Faculty of Medicine, Universitas Gadjah Mada number Ref: KE/FK/234/EC.

5/6 Subtotal nephrectomy procedure and administration of simvastatin

The animals were divided into five groups: the nephrectomy (SN, $\mathrm{n}=6$ ), sham operation ( $\mathrm{SH}, \mathrm{n}=6)$, simvastatin $5.2 \mathrm{mg} / \mathrm{kg}$ body weight (SIM-1, n=6), simvastatin $10.4 \mathrm{mg} / \mathrm{kg}$ body weight (SIM-2, $\mathrm{n}=6$ ), and simvastatin $20.8 \mathrm{mg} / \mathrm{kg}$ body weight (SIM-3, $\mathrm{n}=6$ ) groups. A sham operation procedure was performed on the SH group and a $5 / 6$ subtotal nephrectomy procedure was performed on the $\mathrm{SN}$ and simvastatin (SIM-1, SIM-2, SIM-3) groups and they were terminated after 14 d. Simvastatin (Sigma-Aldrich, Science Park Road, Singapore) was dissolved in a $1 \%$ solution of carboxymethyl cellulose administered once a day by oral gavage (Sigma-Aldrich, St 
Louis, MA, USA). The 5/6 subtotal nephrectomy procedure was performed after anaesthetized with a $0,1 \mathrm{ml} / 10 \mathrm{~g}$ body weight i. p. injection of sodium pentobarbital. In this model, we performed a unilateral nephrectomy on the right kidney and $2 / 3$ of the remaining kidney was ablated by a polar excision $1 \mathrm{~d}$ after the uninephrectomy.

\section{Biochemistry analysis}

Serum creatinine was measured with a kinetic test without deproteinization according to the Jaffe method (DiaSys, Holzheim Germany), proteinuria was measured with a dipstick (YD Diagnostics, Seoul, Korea), total serum cholesterol was measured with the enzymatic photomeric test (DiaSys, Holzheim, Germany) and serum triglyceride was measured with the colorimetric enzymatic test using GPO (DiaSys, Holzheim, Germany).

\section{Morphology}

At the end of the study, the mice were anaesthetized with a $0.1 \mathrm{ml} / \mathrm{g}$ body weight i. p. injection of sodium pentobarbital. The material was then embedded in paraffin for assessment of GS, tubular injury and for immunohistochemical studies. Paraffin-embedded renal tissue was dewaxed using standard sequential techniques, and $4 \mu \mathrm{m}$-thick sections were stained with periodic acid-schiff (PAS). The morphological measurement was performed blindly by a doubleobserver.

The extent of GS was graded from 0 to 4 with a semi quantitative score based on the extent of glomerular damage (sclerosis), capillary loops and synechia between glomerular capillaries and the Bowman's capsule ( 0 , normal; 1 , mesangial expansion/sclerosis involving $<25 \%$ of the tuft; 2, moderate GS (25 to $50 \%$ ); 3, severe GS (50 to $75 \%$ ); and 4 , diffuse GS involving $>75 \%$ of the glomerular tuft). For each kidney, the sum of the results for 20 glomeruli was defined as the glomerulosclerosis index (GSI). The GSI of each mouse was calculated as a mean value of all the glomerular scores obtained [16].

The tubular injury scores were determined through a semiquantitative scoring system. Ten fields were examined for each kidney, and the lesions were graded from 0 to $3(0$, no change; 1 , changes affecting $<25 \%$ of the section; 2 , changes affecting 25 to 50 $\%$ of the section; and 3, changes affecting 50 to $100 \%$ of the section), according to the area with tubulointerstitial lesions (tubular atrophy, tubular dilatation, loss of brush border, intraluminal casts, interstitial inflammation and fibrosis). The score index of each mouse was expressed as a mean value of all scores obtained.

\section{Immunohistochemical (IHC) staining}

The expression of $\alpha$-SMA, a marker of myofibroblast expansion, and PDGF-R $\beta$, a marker of fibroblast were identified through IHC staining using standard techniques. Sections $4 \mu \mathrm{m}$-thick were obtained from paraffin-embedded tissue and subjected to $15 \mathrm{~min}$ microwave heating in citrate buffer for antigen retrieval. Then, slides were incubated with 1:500 monoclonal anti- $\alpha$-SMA (SigmaAldrich, St Louis, MO, USA) and 1:200 anti-PDGF-R $\beta$ (Abcam, Cambridge, USA) overnight in a humidified chamber at $4{ }^{\circ} \mathrm{C}$. The sections were then incubated with appropriate species-specific secondary antibodies (Biocare Medical, Concord, CA, USA) for $1 \mathrm{~h}$ at room temperature. The avidin-biotinylated horseradish peroxidase technique (Biocare Medical, Concord, CA, USA) was used to complete the detection of antigens. The PDGF-R $\beta$ expression was quantified by counting positive cells, and $\alpha$-SMA expression was expressed as fraction area percentage (\%) using Image J software version 1.40. For each section at least 10 consecutive 400x magnification fields of the cortex were examined.

\section{RNA extraction, cDNA synthesis, RT-PCR}

Total RNA was extracted using RNA iso plus (Takara, Otsu, Japan) based on the protocol from the manufacturer, and the RNA concentration was quantified by spectrometry. We used $1000 \mathrm{ng}$ RNA for the cDNA synthesis. cDNA was synthesized using Rever Tra Ace (Toyobo, Osaka, Japan) and random primer (Takara, Otsu, Japan), with the following PCR conditions: $30^{\circ} \mathrm{C}$ for $10 \mathrm{~min}$ (denaturation), $42{ }^{\circ} \mathrm{C}$ for $60 \mathrm{~min}$ (annealing) and $99^{\circ} \mathrm{C}$ for $5 \mathrm{~min}$ (extension).

RT-PCR was carried out to amplify the following specific cDNAs. The primers that were used as: nephrin 5'-CCCCTCTATGATGAAGTACAAATGGA-3' (forward) and 5'-GTACGATTTCCTCAGGTCTTCT-3' (reverse); podocin 5'-GAAAGGAAGAGCATTGCCCAAG-3'(forward) and 5'-TGTGGACAGCGACTGAAGAGTGTG-3'(reverse); ICAM-1 5'-AAACGGGAGATGAATGGTACCTAC-3' (forward) and 5'-TGCACGTCCCTGGTGATACTC-3' (reverse); MCP-1 5'ACTGAAGCTCGTACTCTC-3'(forward) and 5'-CTTGGGTTGTGGAGTGAG-3'(reverse); GAPDH 5'-TCACCATCTTCCAGGAGCG-3' (forward) and 5'-CTGCTTCACCACCTTCTTGA-3' (reverse).

RT-PCR was performed by mixing $2 \mu \mathrm{l}$ of cDNA, $12.5 \mu \mathrm{l}$ of Tag master mix (Bioron, Ludwigshafen, Germany), $0.6 \mu \mathrm{l}$ of forward primer, $0.6 \mu \mathrm{l}$ of reverse primer and $9.3 \mu \mathrm{l}$ of PCR water. The cDNAs were amplified according to the following conditions: $94^{\circ} \mathrm{C}$ for $2 \mathrm{~s}$ (initial denaturation), $94^{\circ} \mathrm{C}$ for $10 \mathrm{~s}$ (denaturation), $60^{\circ} \mathrm{C}$ for $20 \mathrm{~s}$ (the annealing temperature varied for each pair of primers), $72{ }^{\circ} \mathrm{C}$ for $1 \mathrm{~min}$ (extension) and $72{ }^{\circ} \mathrm{C}$ for $10 \mathrm{~min}$ (last extension). The number of cycles was redetermined for each pair of primers in order to avoid the PCR plateau phase. The PCR products were analyzed in $2 \%$ agarose gel along with a $100 \mathrm{bp}$ DNA ladder (Bioron, Ludwigshafen, Germany). The expression of the genes was quantified with a densitometry analysis using the ImageJ software version 1.40. The GAPDH expression was used to normalized the expression.

\section{Statistical analysis}

The results are expressed as mean \pm SEM. multiple comparisons among the groups were done by one-way analysis of variance (ANOVA) and followed by the post hoc Tukey's test. The level of statistical significance was $p<0.05$.

\section{RESULTS}

There was a significant difference in body weight between the SH group $(36.51 \pm 1.11 \mathrm{~g})$ and SN group $(30.51 \pm 3.24 \mathrm{~g})$ at the end of the study. The serum creatinine levels of the SN group $(1.89 \pm 0.32$ $\mathrm{mg} / \mathrm{dl})$ were significantly higher than the SH group $(0.43 \pm 0.04$ $\mathrm{mg} / \mathrm{dl}) 2 \mathrm{w}$ after the operation. There was an increase in plasma creatinine levels and proteinuria in the mice with $5 / 6$ subtotal nephrectomy. However, differences among the level of total cholesterol and triglyceride were not found among the five groups (fig.1). Treatment with simvastatin decreased plasma creatinine levels and attenuated proteinuria, but did not affect the lipid profiles. The following data indicates the pleiotropic effects of statins in mice with nephrectomies.

\section{Glomerulosclerosis, tubular injury score and interstitial fibrosis}

The mice kidneys with $5 / 6$ subtotal nephrectomy developed conspicuous GS and tubular injury consisting of tubular dilatation and atrophy, intraluminal casts, interstitial inflammation and a marked interstitial fibrosis as shown by quantification of GSI and tubular injury score in SN group compared to $\mathrm{SH}$ group. Glomerulosclerosis index and tubular injury score on PAS staining showed that simvastatin significantly attenuated GS $(2.39 \pm 0.34$ vs $3.95 \pm 0.06, \mathrm{p}<0.05$, SIM- 1 vs $\mathrm{SN} ; 2.23 \pm 0.49$ vs $3.95 \pm 0.06, \mathrm{p}<0.05$, SIM-2 vs SN; $1.98 \pm 0.23$ vs $3.95 \pm 0.06, p<0.05$, SIM- 3 vs SN) and tubular injury $(2.19 \pm 0.32$ vs $3.97 \pm 0.04, p<0.05$, SIM- 1 vs $S N$; $1.78 \pm 0.36$ vs $3.97 \pm 0.04, \mathrm{p}<0.05$, SIM- 2 vs $S N ; 1.63 \pm 0.67$ vs $3.97 \pm 0.04, \mathrm{p}<0.05$, SIM-3 vs SN) (fig. 2).

\section{Myofibroblast and fibroblast expansion}

In the kidneys of the SH group, $\alpha$-SMA was expressed in the smooth muscle cells of renal arterioles, whereas $5 / 6$ subtotal nephrectomy caused an increase in the expression of $\alpha$-SMA positive cells in the interstitium compartment known as myofibroblast. Meanwhile, simvastatin treatment significantly reduced myofibroblast fraction area $(3.61 \pm 1.06$ vs $7.91 \pm 1.26, p<0.05$, SIM- 1 vs $S N ; 2.86 \pm 0.61$ vs $7.91 \pm 1.26, p<0.05$, SIM- 2 vs SN; $1.71 \pm 0.50$ vs $7.91 \pm 1.26, p<0.05$, SIM-3 vs SN) (fig.3). 

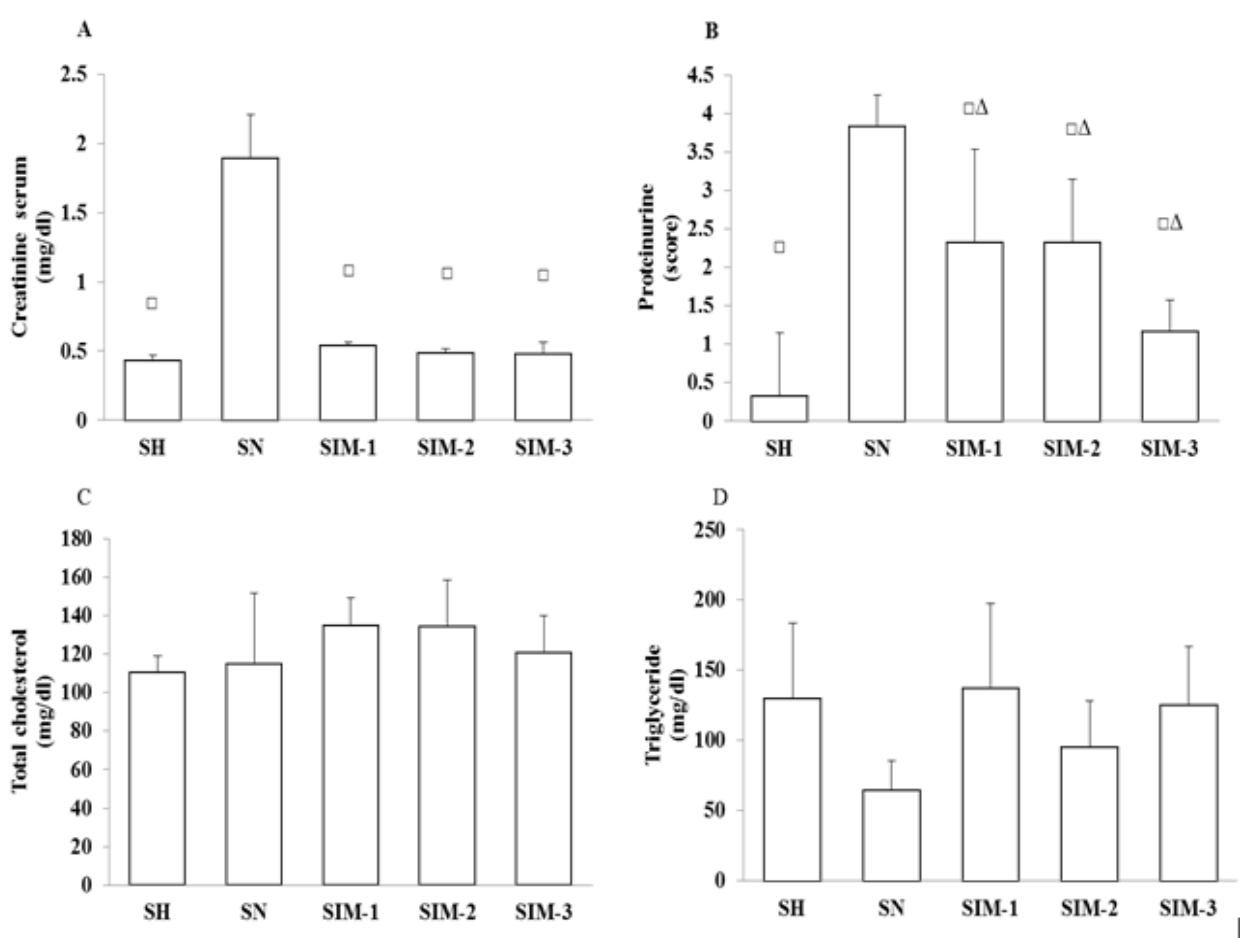

Fig. 1: Effect of simvastatin on creatinine serum, proteinuria, total cholesterol, and triglyceride. $\square=p<0.05$ vs $\mathrm{SN}, \Delta=p<0.05$ vs $\mathrm{SH}$, $\mathrm{SH}$ (sham operation), SN (5/6 subtotal nephrectomy), SIM (5/6 subtotal nephrectomy+simvastatin)

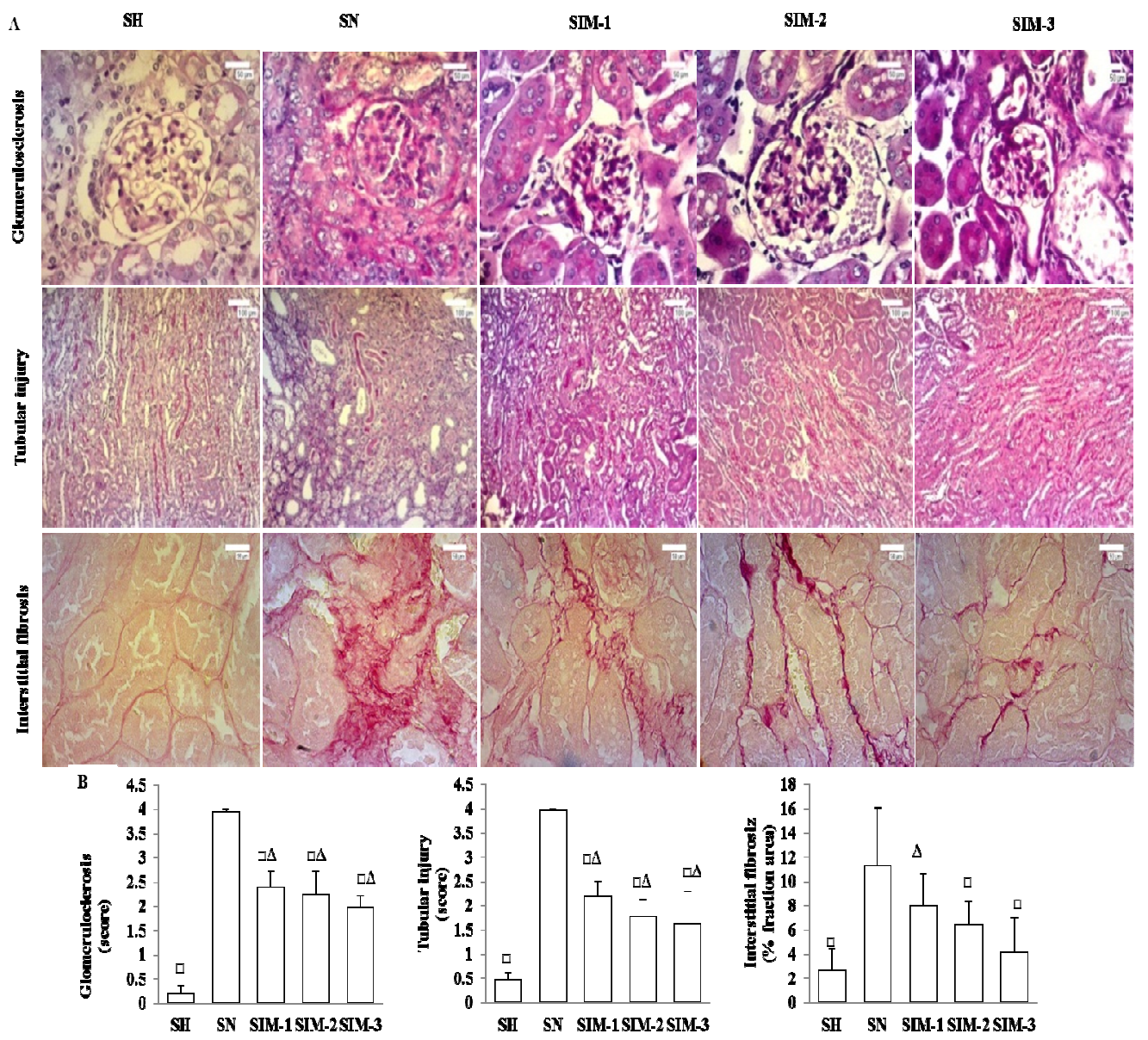

Fig. 2: (A) Renal histological changes evaluated with PAS staining and interstitial fibrosis evaluated with Picrosirus Red. (B) The bar graph summarizes the number of GS, tubular injury score and interstitial fibrosis. $\square=p<0.05$ vs $\mathrm{SN}, \Delta=p<0.05$ vs SH, SH (sham operation), SN (5/6 subtotal nephrectomy), SIM (5/6 subtotal nephrectomy+simvastatin) 


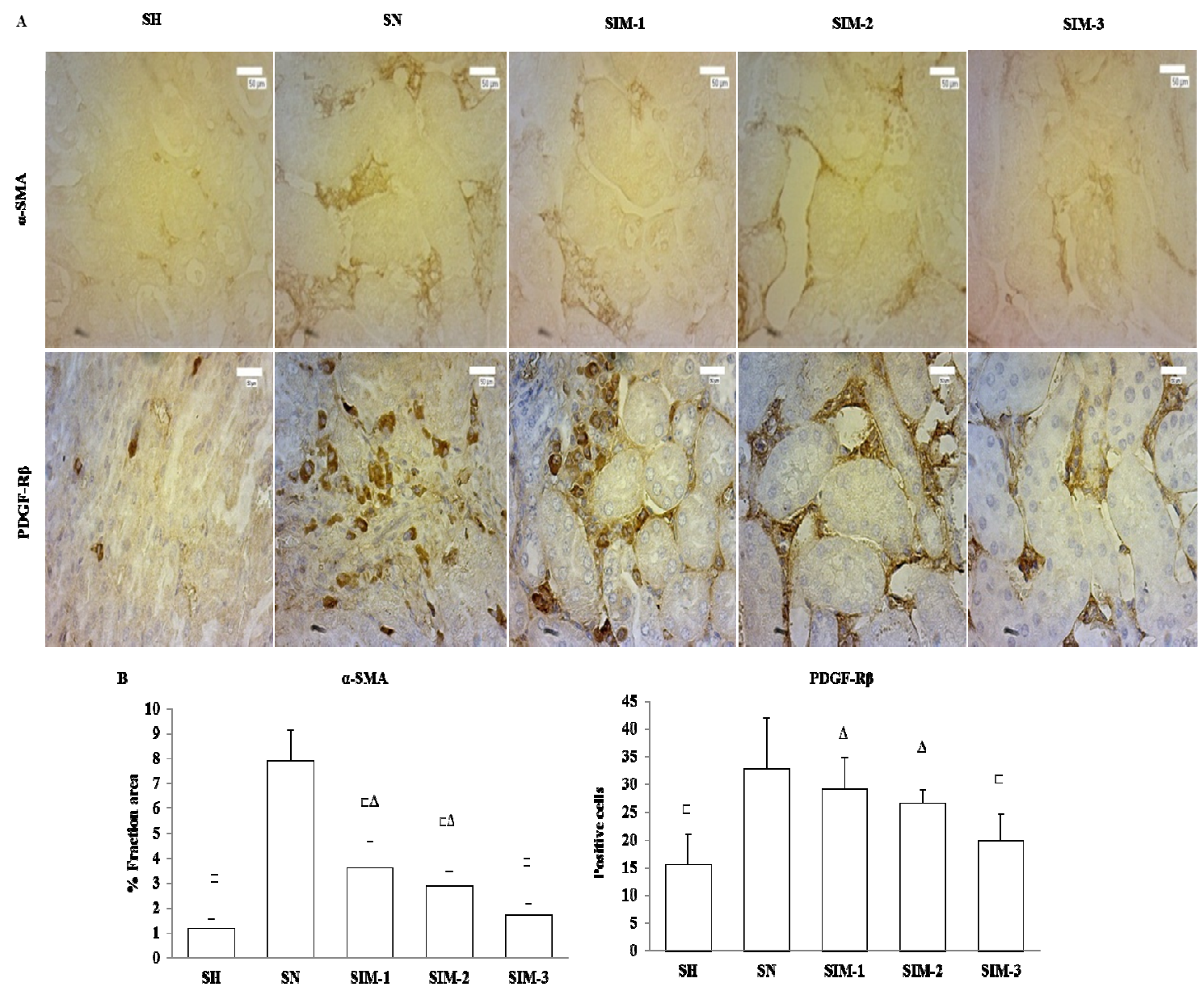

Fig. 3: (A) Immuno-histochemical analysis of $\alpha$-SMA and PDGF-R $\beta$. (B) Bar graph summarizes a number of $\alpha$-SMA and PDGF-R $\beta$. $\square=p<0.05$ vs SN, $\Delta=p<0.05$ vs SH, SH (sham operatian), SN (5/6 subtotal nephrectomy), SIM (5/6 subtotal nephrectomy+simvastatin)

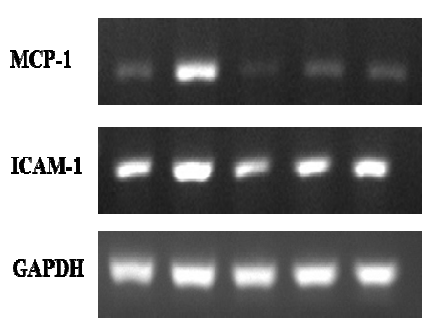

SH SN SIM1 SIM 2 SIM 3
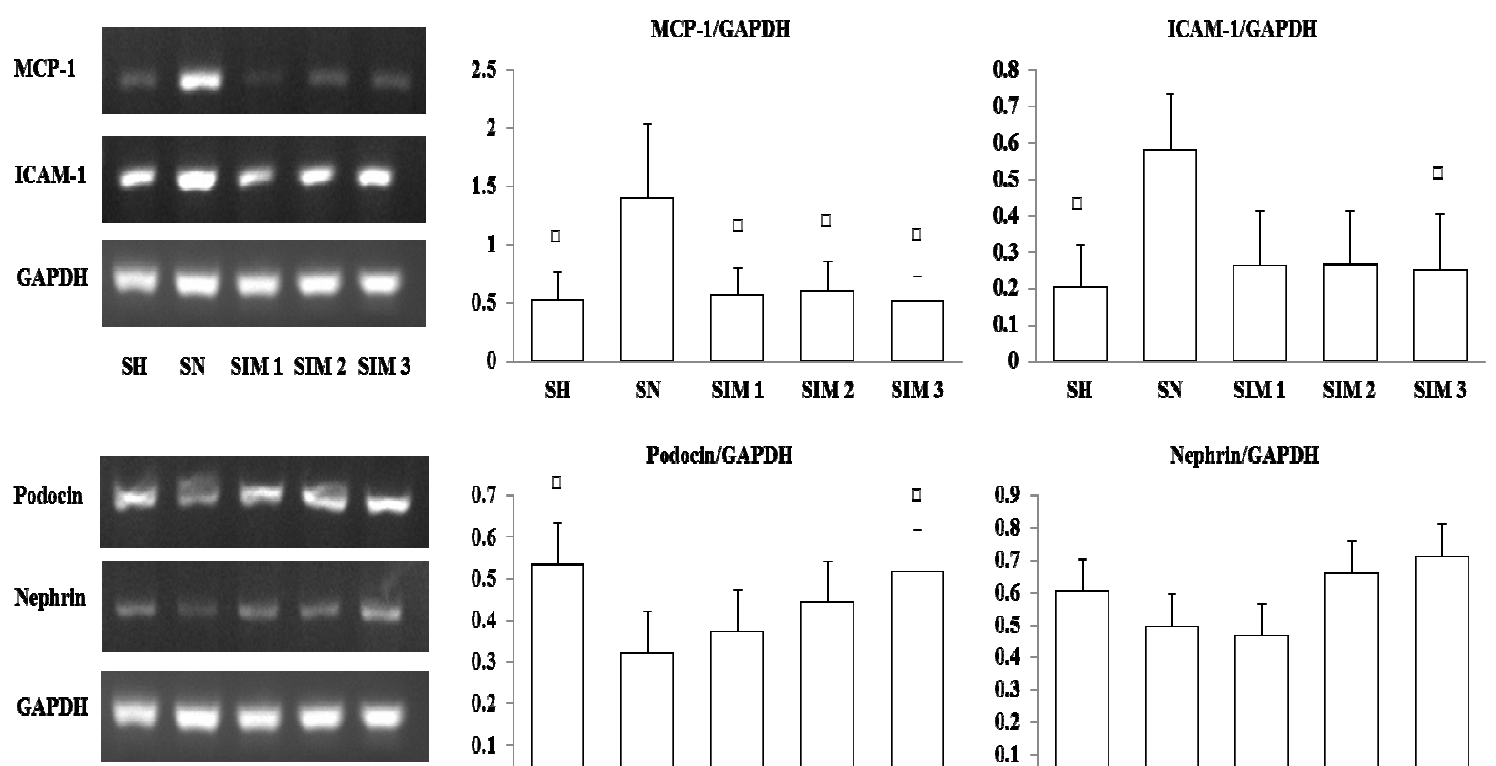

SH SN SIM1 SIM2 SIM3
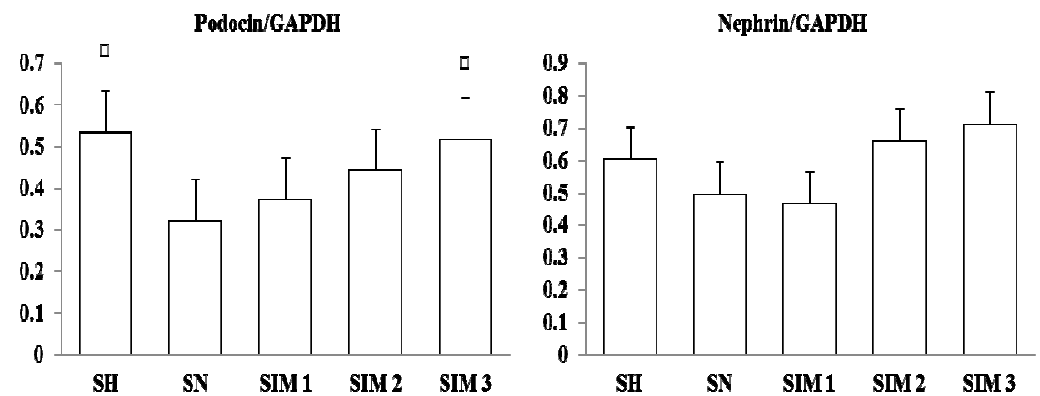

Fig. 4: (A) Representative gels of MCP-1, ICAM-1, nephrin and podocin expressions. (B) Densitometric analysis of MCP-1, ICAM-1, nephrin and podocin protein expressions. $\square=p<0.05$ vs $\mathrm{SN}, \Delta=p<0.05$ vs SH, SH (sham operatian), SN (5/6 subtotal nephrectomy), SIM (5/6 subtotal nephrectomy+simvastatin) 


\section{MCP-1, ICAM-1, nephrin and podocine expression}

In order to investigate the status of podocyte integrity and inflammatory markers in mice with 5/6 subtotal nephrectomy, we studied the expressions of nephrin, podocin, MCP-1, and ICAM-1. In this study, the MCP-1 and ICAM-1 expressions of the SN group were significantly higher than the SH group. Treatment with simvastatin reduced this expression significantly. The nephrin expression in the SN group was lower than the SH group, though this was not statistically significant. Treatment with simvastatin was able to improve this expression, but this was also not statistically significant. Amelioration of podocyte integrity was shown by higher expression of podocin in simvastatin treatment groups compare to SN group. Contrast to the nephrin expressions, podocin expression in the SN group was significantly lower than the SH group $(0.32 \pm 0.12$ vs $0.53 \pm 0.09, \mathrm{p}<0.05$, SN vs $\mathrm{SH})$. Simvastatin treatment in the SIM-3 group also appeared to attenuate podocin expression significantly than in the SN group $(0.52 \pm 0.1$ vs $0.32 \pm 0.12, p<0.05$, SIM-3 vs SN) (fig. 4).

\section{DISCUSSION}

Two weeks of 5/6 subtotal nephrectomy was associated with loss of functional nephrons which induced glomerular hyperfiltration, compensatory renal hypertrophy, systemic hypertension, and functional and morphological damage of the remaining kidney [1517]. As expected, in this study the $5 / 6$ subtotal nephrectomy mice showed impaired renal function and proteinuria, accompanied by severe GS, tubular injury and interstitial fibrosis, as well as myofibroblast expansion.

Renal function impairment is characterized by increased levels of serum creatinine and proteinuria in the $\mathrm{SN}$ group compared with the $\mathrm{SH}$ group. Statins have been reported to reduced the levels of serum creatinine [18-20], C-reactive protein, BUN, eGFR and proteinuria $[14,18,20,21]$, which is consistent with the results of this study. The duration and dose of the therapy appears to have affected these renoprotective effects $[13,14]$. However, a study on an NO deficiency model reported no difference in the levels of serum creatinine after administration of statins among the groups [22]. Proteinuria may occur as a result of glomerular filtration and tubular reabsorption dysfunction [20]. Statins may moderately reduce pathologic excretion of urine albumin and proteinuria within a period of 6 mo after initiation of the therapy and may reduce the rate of kidney disease progression when combined with RAASI [22,23].

Dyslipidemia is a major problem in CKD, which lead to higher risk of $\mathrm{CV}$ disease and renal function deterioration $[4,25]$. The results of previous studies suggest that statins have pleiotropic effects in a cholesterol-independent reduction manner [19, 22, 26-30], though the mechanisms have not been sufficiently revealed yet. The total cholesterol and triglyceride levels between treatment groups in this study showed no significant differences $(p<0.05)$. These results indicate that simvastatin can improve kidney function, but have no effect on cholesterol levels and triglyceride. However, other studies have reported that administration of atorvastatin $100 \mathrm{mg} / \mathrm{kg} / \mathrm{d}$ significantly lowers total cholesterol, LDL, VLDL, and improves HDL [30], reduces TC concentrations by $13 \%$ in patients with CKD, have protective effects on CV events and mortality in patients with or without established CV diseases [4]. The decrease in LDL levels was parallel to the increasing doses of statins and significantly different between the statin types used, however this had no significant implications on clinical practice [31].

In this study, treatment with simvastatin reduced the GS, tubular injury score and interstitial fibrosis. The results of the semi quantitative analysis on GS and tubular injury score in the simvastatin groups (SIM-1, SIM-2, SIM-3) were significantly lower than SN group $(p<0.05)$. Glomerulosclerosis is associated with extracellular matrix deposition, abnormal mesangial cell expansion and increased kidney inflammation [11]. Simvastatin prevents GS through anti-inflammatory effects such as decreased proinflammatory cytokines (IL-6, IL-1 $\beta$, TGF- $\beta$ and TNF- $\alpha$ ) $[10,22]$, decreased NF- $\mathrm{KB}$ expression [10], and increased hepatocyte growth factor, BMP-7 and Smad 7 expressions which improves renal blood flow [28]. Simvastatin is also known to improve $24 \mathrm{~h}$ urine albumin excretion ratio and increase nephrin expression [7]. In this study we found that there was no significant difference in nephrin expression between the groups $(p>0.05)$. However, in the SIM-3 group, treatment with simvastatin appeared to reduce podocin expression significantly.

In contrast to the glomerular lesion, the tubular injury was predominantly caused by an increase in total interstitial cell volume (which may represent increased cell size and/or number), preceding the accumulation of interstitial collagen. These interstitial cells include myofibroblast cells, which have pivotal roles as a major source of collagen synthesis in interstitial fibrosis and increased expression of $\alpha$ SMA [32, 33]. Previous studies have reported that simvastatin can slow fibrosis by decreasing CTGF and $\alpha$-SMA expressions in a diabetic nephropathy model [34], preventing the activation and trans differentiation of tubular cells (decreasing type 1 collagen, fibronectin, $\alpha$-SMA, and vimentin expressions) [25], as well as reducing MCP- 1 and p21 expresions [27]. In this study, we also found that simvastatin reduced MCP-1 expression at 3 different doses and reduced ICAM- 1 at the highest dose $(20.8 \mathrm{mg} / \mathrm{kg}$ body weight).

Alpha-SMA is an intermediate filament used as a marker for myofibroblast. In normal mice kidneys, $\alpha$-SMA expression is limited to the vascular smooth muscle artery [35, 36]. Based on data from this study, we found that treatment with simvastatin reduced the expansion of myofibroblast at each of the given doses. Decreased $\alpha$ SMA was also reported through treatment with $2 \mathrm{mg} / \mathrm{kg}$ simvastatin on a UUO model [25]. These results are similar with other in vitro studies in which simvastatin inhibits the production of $\alpha$-SMA in keloid fibroblasts [37], blocks calcific nodule formation in valvular interstitial cells by inhibiting $\alpha$-SMA expression [38]. Here we revealed simvastatin effect on attenuating kidney injury independent to its lowering lipid effect. lipid lowering-independent effect of simvastatin is also known into decreasing human atrial myofibroblast proliferation regardless of cholesterol decrease via inhibition of RhoA [39]. Furthermore, simvastatin-induced cardiac fibroblast cytoskleton, adhesion, migration and viability [40]. Meanwhile, other study also revealed nephrotoxicity effect of high dose atorvastatin independent to oxidative stress but may be due to rhabdomyolisis [41]. For future studies, it is needed to consider the dose-dependent effect of statin in renal patology.

\section{CONCLUSION}

In conclusion, in this model, simvastatin significantly attenuated kidney fibrosis. These effects can be seen through the decrease in GS, tubular injury and interstitial fibrosis which appear to result from the reduction of myofibroblast expansion and inflammatory mediators. Beyond its effect, statins might prove to be an effective adjunctive treatment in renal disease.

\section{CONFLICT OF INTERESTS}

The authors would like to thank Titik Cahyanti, MD, Hayu Qaimamunazzala, MD and Mr. Mulyana for technical support during this study. This study was funded by Penelitian Unggulan Perguruan Tinggi 2014-2015 of Indonesian Government. Some of the results of this study was used for finishing master programme for Putu Nita Cahyawati in 2015 from Health Science and Biomedical Science Graduate School, Faculty of Medicine, Universitas Gadjah Mada, Yogyakarta, Indonesia.

\section{REFERENCES}

1. Hamasaki Y, Doi K, Okamoto K, Ijichi H, Seki G, Maeda-Mamiya R, et al. 3-hydroxy-3-methylglutaryl-coenzyme a reductase inhibitor simvastatin ameliorates renal fibrosis through HOXA13-USAG-1 pathway. Laboratory Investigation 2012;92:1161-70.

2. Lopez-Novoa JM, Martinez-Salgado C, Rodriguez-Pena AB, Hernandez FJL. Common pathophysiological mechanisms of chronic kidney disease: therapeutic perspectives. Pharmacol Ther 2010;128:61-81.

3. Babelova A, Jansen F, Sander K, Lohn M, Schafer L, Fork, C, et al. Activation of rac- 1 and rhoA contributes to podocyte injury in chronic kidney disease. Plos One 2013;8:e80328.

4. Sheng X, Murphy MJ, Macdonald TM, Wei L. Effectiveness of statins in chronic kidney disease. QJ Med 2012;105:641-8. 
5. Laufs U, Liao JK. Isoprenoid metabolism and the pleiotropic effects of statins. Curr Atheroscler Rep 2003;5:372-8.

6. Tristano AG, Fuller K. Immunomodulatory effects of statins and autoimmune rheumatic diseases: novel intracellular mechanism involved. Int J Immunopharmacol 2006;6:1833-46.

7. Wei P, Grimm PR, Settles DC, Balwanz CR, Padanilam BJ, Sansom SC. Simvastatin reverses podocyte injury but not a mesangial expansion in early stage type 2 diabetes mellitus. Renal Failure 2009;31:503-13.

8. Diez RR, Rodrigues-Diez R, Lavoz C, Rayego-Mateos S, Civantos E, Rodriiguez-Vita J. Statins inhibit angiotensin II/smad pathway and related vascular fibrosis, by a TGF-b-independent process. Plos One 2010;5:e14145.

9. Toba H, Mitani T, Takahashi T, Imai N, Serizawa R, Wang J, et al. Inhibition of the renal renin-angiotensin system and renoprotection by pitavastatin in type 1 diabetes. Clin Exp Pharmacol Physiol 2010;37:1064-70.

10. Zhang W, Li Q, Wang LJ, Yang XQ. Simvastatin ameliorates glomerulosclerosis in adriamycin-induced-nephropathy rats. Pediatr Nephrol 2008;23:2185-94.

11. Zhou MS, Schuman IH, Jaimes EA, Raij L. Renoprotection by statins is linked to a decrease in renal oxidative stress, TGF- $\beta$, and fibronectin with a concomitant increase in nitric oxide bioavailability. Am J Physiol Renal Physiol 2008;295:F53-9.

12. Haynes R, Lewis D, Emberson J, Reith C, Agodoa L, Cass A, et al. Effects of lowering ldl cholesterol on the progression of kidney disease. J Am Soc Nephrol 2014;25.

13. Nikolic D, Banach M, Nikfar S, Salari P, Mikhailidis DP, Toth PP, et al. A meta-analysis of the role of statins on renal outcomes in patients with chronic kidney disease. Is the duration of therapy important?. Int J Cardiol 2013;168:5437-47.

14. Geng Q, Ren J, Song J, Li S, Chen H. Meta-analysis of the effect of statins on renal function. Am J Cardiol 2014;114:562-70.

15. Gava AL, Freitas FPS, Balarini CM, Vasquez EC, Meyrelles SS. Effects of 5/6 nephrectomy on renal function and blood pressure in mice. Int J Physiol Pathophysiol Pharmacol 2012;4:67-73.

16. Inui $Y$, Mochida $\mathrm{H}$, Yamairi F, Okada M, Ishida J, Fukamizu A, et al. Effects of aging and uninephrectomy on renal changes in tsukuba hypertensive mice. Biomedical Reports 2013;1:359-64.

17. Nagasu H, Satoh M, Kidokoro K, Nishi Y, Channon KM, Sasaki T, et al. Endothelial dysfunction promotes the transition from compensatory renal hypertrophy to kidney injury after unilateral nephrectomy in mice. Am J Physiol Renal Physiol 2012;302:F1402-8.

18. Christensene M, Su AW, Snyder RW, Greco A, Lipschutz JH, Madaio MP. Simvastatin protection against acute immunemediated glomerulonephritis in mice. Kidney Int 2006; 69:457-63.

19. Bae EH, Kim IJ, Park JW, Ma SK, Lee JU, Kim SW. Renoprotective effect of rosuvastatin in DOCA-hypertensive salt rats. Nephrol Dial Transplant 2010;25:1051-9.

20. Shibata S, Nagase M, Fujita T. Fluvastatin ameliorates podocyte injury in proteinuric rats via modulation of excessive rho signalling. J Am Soc Nephrol 2006;17:754-64.

21. Reddy VC, Amulya V, Lakshmi CHA, Reddy DBPK, Pratima D, Thirupathi AT, et al. Effect of simvastatin in gentamicininduced nephrotoxicity in albino rats. Asian J Pharm Clin Res 2012;5:36-40.

22. Girardi JM, Farias RE, Ferreira AP, Raposo NRB. Rosuvastatin prevents proteinuria and renal inflammation in nitric oxidedeficient rats. Clinics 2011;66:1457-62.

23. Douglas K, O'Malley PG, Jackson JL. Meta-analysis: the effect of statins on albuminuria. Ann Intern Med 2006;145:117-25.

24. Bianchi S, Bigazzi R, Caiazza A, Campese VM. A controlled, prospective study of the effects of atorvastatin on proteinuria and progression of kidney disease. Am J Kidney Dis 2003; 41:565-70.
25. Nitta K. Clinical assessment and management of dyslipidemia in patients with chronic kidney disease. Clin Exp Nephrol 2012;16:522-9.

26. Vieira JM, Mantovani E, Rodrigues LT, Delle H, Noronha IL, Fujihara CK, et al. Simvastatin attenuates renal inflammation, tubular transdifferentiation and interstitial fibrosis in rats with unilateral ureteral obstruction. Nephrol Dial Transplant 2005;20:1582-91.

27. Vieira JM, Rodrigues LT, Mantovani E, Delle H, Mattar AL, Malheiros DM, et al. Statin monotherapy attenuates renal injury in a salt-sensitive hypertension model of the renal disease. Nephron Physiol 2005;101:82-91.

28. Chade AR, Zhu XY, Grande JP, Krier JD, Lerman A, Lerman LO. Simvastatin abates development of renal fibrosis in experimental renovascular disease. J Hypertens 2008;26: 1651-60.

29. Yagi S, Aihara K, Ikeda Y, Sumitomo Y, Yoshida S, Ise T, et al. Pitavastatin, an HMG-CoA reductase inhibitor, exerts eNOSindependent protective actions against angiotensin II-induced cardiovascular remodeling and renal insufficiency. Circ Res 2008;102:68-76.

30. Nachtigal P, Pospisilova N, Vecerova L, Micuda S, Brcakova E, Pospechova K, et al. Atorvastatin increases endoglin, SMAD2, phosphorylated SMAD2/3 and eNOS expression in ApoE/lDLR double knock out mice. J Atheroscler Thromb 2009;16:265-74.

31. Weng TC, Yang YH, Lin SJ, Tai SH. A systematic review and meta-analysis on the therapeutic equivalence of statins. J Clin Pharm Ther 2010;35:139-51.

32. Fogo AB. Mechanisms of progression of chronic kidney disease. Pediatr Nephrol 2007;22:2011-22.

33. Katz A, Caramori ML, Sisson-Ross S, Groppoli T, Basgen JM, Mauer M. An increase in the cell component of the cortical interstitium antedates interstitial fibrosis in type 1 diabetic patients. Kidney Int 2002;61:2058-66.

34. Lin FL, Shen HC, Zhu B, Lin KQ. Effects of simvastatin on the expression of CTGF and $\alpha$-SMA in renal tubulointerstitium of rats with diabetic nephropathy. J Zhejiang Univ 2010;39:511-6.

35. Campanholle G, Ligresti G, Gharib SA, Duffield JS. Cellular mechanisms of tissue fibrosis. 3. Novel mechanisms of kidney fibrosis. Am J Physiol Cell Physiol 2013;304:C591-603.

36. Nakagawa N, Duffield JS. Myofibroblasts in fibrotic kidneys. Curr Pathobiol Rep 2013;1:1-14.

37. Mun JH, Kim YM, Kim BS, Kim JH, Kim MB, Ko HC. Simvastatin inhibits transforming growth factor- $\beta 1$-induced expression of type 1 collagen, CTGF, and $\alpha$-SMA in keloid fibroblasts. Wound Rep Reg 2014;22:125-33.

38. Benton JA, Kern HB, Leinwand LA, Mariner PD, Anseth KS. Statins block calcific nodule formation of valvular interstitial cells by inhibiting $\alpha$-smooth muscle actin expression. Arterioscler Thromb Vasc Biol 2009;29. Doi:10.1161/ atvbaha.109.195271

39. Porter KE, Turner NA, O’Regan DJ, Balmforth AJ, Ball SG. Simvastatin reduces human atrial myofibroblast proliferation independently of cholesterol lowering via inhibition of rhoA. Cardiovasc Res 2004;61:745-55.

40. Copaja M, Venegas D, Aranguiz P, Canales J, Vivar R, Avalos Y, et al. Simvastatin disrupts cytoskeleton and decreases cardiac fibroblast adhesion, migration and viability. Toxicology 2012;294:42-9.

41. Panonnummal R, Varkey J. Statin-induced nephrotoxicity: a dose dependent study in albino rats. Int J Pharm Sci 2014;6:401-6.

\section{How to cite this article}

- Putu Nita Cahyawati, Ngatidjan, Dwi Cahyani Ratna Sari, Muhammad Mansyur Romi, Nur Arfian. Simvastatin attenuates renal failure in mice with A 5/6 subtotal nephrectomy. Int J Pharm Pharm Sci 2017;9(5):12-17. 